\title{
Research on layout of multimodal transport center in Jinan City
}

\author{
Xue Qin ZHANG ${ }^{1, *}$, Ying Ran CUI ${ }^{1}$, Yuan $\mathrm{LI}^{1}$, and Xiu Feng LIANG ${ }^{1}$ \\ ${ }^{1}$ Shandong Jiaotong University, Ji'nan, Shandong 250300, China
}

\begin{abstract}
Multimodal operation is an efficient form of transportation organization. By integrating various modes of transport, the advantages of each mode are fully exerted, and the efficiency and quality of transportation are improved to meet the demand for personalized transport. This article first analyzes the status of multimodal transport development in various regions of Shandong Province; through the analysis of the external environment in which Jinan City is located, it proposes the layout of the Jinan Multimodal Transport Center; finally, it proposes various solutions based on the actual development status.
\end{abstract}

\section{Introduction}

With the development of society, people pay more and more attention to the efficiency of transport. In this case, multimodal transport has emerged as the times require. It depends on the combination of sea and land, land and land, and so on, which greatly reduces the transportation time and saves manpower. Most multimodal transport today relies on large containers for loading and unloading of goods. Although China started early in multimodal transport, mainly because of the early system and facilities not perfect, missed a golden development period. Fortunately, the government has noticed the high efficiency and importance of multimodal transport, actively establish and improve the relevant legal system and facilities, so multimodal transport has been redeveloped at a high speed. With the development of our economy and the acceleration of the pace of opening to the outside world, the requirements of inland multimodal transport and international multimodal transport are becoming more and more intense. With the development of the times, logistics is developing rapidly. Multimodal transport as an important branch is concerned by people from all walks of life. Under the background of increasingly intense competition, "multimodal transport" has also been developing rapidly.

\section{Analysis on Current Situation of Multimodal Transport in Shandong}

\subsection{Shandong Economic Development Analysis}

In 2015, Shandong was China's economic province. Since the implementation of the "13th Five-Year Plan", its overall economic strength has been steadily improving. In 2017, the province's GDP reached 7.267818 trillion yuan, an increase of $7.4 \%$ over the previous year, as shown in Table 1 .
Table.1 2011-2017Shandong Province GDP and industrial structure ratio

\begin{tabular}{|c|c|c|}
\hline Years & GDP/ Billion & $\begin{array}{c}\text { The proportion of } \\
\text { three industries }\end{array}$ \\
\hline 2011 & 45429.2 & $8.8: 52.9: 38.3$ \\
\hline 2012 & 50013.2 & $8.6: 51.4: 40.0$ \\
\hline 2013 & 54684.3 & $8.7: 50.1: 41.2$ \\
\hline 2014 & 59426.6 & $8.1: 48.4: 43.5$ \\
\hline 2015 & 63002.3 & $7.9: 46.8: 45.3$ \\
\hline 2016 & 1604 & $7.3: 45.4: 47.3$ \\
\hline \multicolumn{3}{|c|}{ (Source: China Statistical Yearbook) } \\
\hline
\end{tabular}

\subsection{Analysis on the Development Status of Multimodal Transport in Shandong Province}

There are a total of 17 cities in Shandong Province. The development of multimodal transport in different cities is different. This paper selects Jinan, Qingdao and Weifang as the objects to analyze the development of multimodal transport in three cities with economic strength and geographical location.

(1) Jinan: Jinan is relying on the construction of railway logistics parks such as Shandong Ji'er Jiaozhou transport of railway containers. The Shandong Jiaozhou Jiaozhou Logistics Park Project was established solely by the Jinan Railway Bureau. It has five railway lines and a comprehensive modern logistics park centered on multimodal transportation of land, sea and air.

(2) Qingdao: In June 2016, the Qingdao "Belt and Road" cross-border container multimodal transport project was approved by the state and the only multimodal transport demonstration project in Shandong Province. The first multimodal customs supervision center in the coastal area of China-Qingdao Multimodal Customs Supervision Center achieved a total volume of shipments of more than 420,000 TEUs in 2017 , an increase of $18.3 \%$ year-on-year, ranking fourth in the national railway container terminal. In 2017, the

\footnotetext{
* Corresponding author: 1454033921@qq.com
} 
"One Belt and One Road" multimodal logistics bidirectional logistics hub centered on Qingdao Central Station was gradually formed. It was also the opening of two international trains of China-EU Classes and "ASEAN Special Lines".

(3) Weifang: The construction progress of expressway projects ranks in the forefront of the province, and the construction of "two-ring and sixshots" comprehensive transport corridors has been carried out in an orderly manner, forming the "One Belt and One Road" large-scale thoroughfare for full docking, vertical and horizontal development of the layout, and Luliao land and sea freight. Roll off the big transport lanes. It opened up the sea transportation channel for North China-Northeast commodity vehicles and agricultural equipment, and opened up the international major channel of "Liaoying Manchu and Europe".

The development of Shandong multimodal transport is steadily developing in recent years. Among them, the development of Qingdao is in a leading position in Shandong, and Jinan and Weifang are also steadily developing.

\section{Analysis of the external environment of multimodal transport development in Jinan}

\subsection{Policy support for the development of multimodal transport}

In the thirteenth Five-Year plan outline, the People's Republic of China clearly put forward the development plan of container multimodal transport. The key task is to improve the function of multimodal transport channels and strengthen the construction of comprehensive hubs. On June 3rd 2015 recently, the Department of Communications and Transport of Shandong Province, the Department and Reform Commission of Shandong Province and other 24 departments jointly formulated the "Implementing the 18 sector notification of the Ministry of transportation and other departments to promote the implementation of multimodal transport in Shandong" .By the end of "the 13th Five-Year plan,in Shandong Province, a multimodal transport system with reasonable layout, advanced technology, perfect facilities, convenient and efficient, integrated linkage, green environmental protection, safe and orderly multimodal transport system has been established, and a modern multimodal transport system has basically been established. ${ }^{[1]}$ Before end of 2017, the Provincial Bureau of Communications and Transportation and Jinan Railway Bureau signed the "Cooperation Agreement on Joint Promotion of Multimodal Transport Development Strategy", forming a cooperative propulsion mechanism.

\subsection{The thrust of multimodal transport}

Shandong Province vigorously promoted the construction of transportation infrastructure, while the economic strength of transportation continued to grow. The investment of natural assets in the year was 78 billion 300 million yuan, an increase of $21 \%$, reaching a new high of history and exceeding the target.The total mileage of the highway is 265 thousand and 800 kilometers, and the road density is $169.6 \mathrm{~km}$ per 100 square kilometers. Shandong province business vehicles increased to 1 million 26 thousand vehicles, including 1 million trucksand 26 thousand passenger cars. The total transportation capacity of Shandong sea river is 19 million 80 thousand tons, and the average tonnage of a single vessel has increased to 1511 tons.

\subsection{The economic power of multimodal transport in Jinan}

Shandong's Gross Domestic Product (GDP) ranks third in the country, accounting for $1 / 9$ of China's total GDP. In the past five years, Shandong's economy has continued to develop steadily, while the economy of Ji'nan city is in a steady state. In 2017, the total GDP of the city was 7 trillion and 267 billion 818 million yuan, an increase of 7.4 percent over the previous year. Jinan is the capital city of Shandong Province and the economic city of Shandong Province, which gathers a large number of professional technicians in there. Therefore, the advantages of the labor population in Jinan and the high quality of the labor provide a solid foundation for the development of multimodal transport in Jinan.

\section{The layout of Jinan multimodal transport center}

\subsection{Analysis of internal function area of jinan multimodal transport center}

(1) Storage area: used to store goods from the customer or port to the intermodal center, which can effectively organize the source of goods and increase the operational capacity of the center.

(2) Transit area: as a freight transit station between the transportation center and the customer, it can reduce the cost to a certain extent by reducing the inventory pressure and increasing the efficiency of transit.

(3) Loading and unloading handling area: the center is equipped with specialized handling 
machinery to improve operation efficiency, reduce damage caused by operation and reduce operation cost.

(4) Delivery area: it is necessary to arrange delivery time and goods reasonably to avoid confusion and waste of time ,which caused by various goods.

(5) Customs declaration and inspection area: in order to meet the needs of multimodal transport, the center establishes customs declaration and inspection areas to declare goods inland, declare inspection, issue bills of lading, ship them directly to port, transport, lighten the pressure on the ports, and improve the throughput, reduce the retention time. To some extent, improve the income and reduce the cost.

(6)Information control center: build the information platform of transportation center, realize the information sharing of Anhydrous port, customers and shippers. Such as: cargo tracking system, information release, vehicle stowage and so on.

(7) Packaging area: according to the requirements of customers, we can make some necessary packing for the goods to reduce the wear and tear of the goods, increase the beauty and reduce the risk of transportation.

(8) Parking area: the parking area of the freight car and the two parts of the social vehicle parking area, which are used to park the freight vehicles in the park and temporary parking for customers and employees.

(9) Circulation processing zone: the goods can be processed according to the requirements of customers, w-hich can not only attract consumers' eyeballs, but also increase the profit of goods.

(10) Distribution and sorting area: the center can sort the goods and distribute the goods according to the customer's demand. When delivering the goods, we should fully consider the distribution route and so on, so as to deliver the goods to the customers with the minimum cost and the highest efficiency ${ }^{[2]}$.

\subsection{Layout of Jinan multimodal transport center}

\section{(1) Jinan External Highway Network}

Jinan is located in the middle and western part of Shandong Province and has obvious location advantages. At the end of 2016, the highway mileage was 1,2730.2 kilometers. Jinan has a relatively developed transportation system. Jinan's external road network is shown in Figure 1. On December 28, 2016, Jidong Expressway was officially opened to traffic. It is one of the "two-ring, twelve-shot" high-speed road network routes in Jinan and is the "Five Vertical, Four Horizontal, One Ring, Eight Link" highway network in Shandong Province. The middle part is also an important channel connecting the Jinan metropolitan area in the strategic layout of the development of the highly efficient ecological economic zone in the Yellow River Delta.

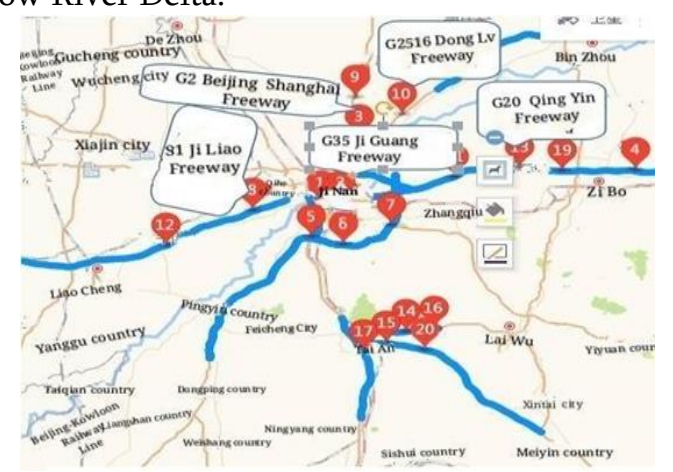

Fig.1. Ji'nan highway network ombined

(2) Railway network of Jinan

Jinan is in the key position through the four corners of the world. Jinan city, as the capital city of shandong province, has provided strong momentum for the steady economic growth of shandong. Table.2 total imports and exports by category of jinan

\begin{tabular}{|c|c|c|c|}
\hline Years & $\begin{array}{c}\text { Total import } \\
\text { and export }\end{array}$ & Total imports & Total export \\
\hline 2010 & 743776 & 338888 & 404888 \\
\hline 2011 & 1041422 & 436966 & 604456 \\
\hline 2012 & 913286 & 341844 & 571442 \\
\hline 2013 & 957442 & 409126 & 548316 \\
\hline 2014 & 1048867 & 442950 & 605817 \\
\hline 2015 & 911424 & 311763 & 599661 \\
\hline 2016 & 929391 & 592765 & 336626 \\
\hline
\end{tabular}

(Source: Jinan Statistical Yearbook 2016.)

Foreign trade in Jinan City has increased. As shown in Table 2, Jinan City's import and export goods have increased, and Jinan's inland economic level has improved. This provides favorable conditions for the Jinan Inland Construction Intermodal Center. In addition, the railway network in Shandong Province includes the trunk lines in Shandong Province of the Beijing-Shanghai and Beijing-Kowloon Railways, the Blue Smoke Line, the Yanshi Line, the Jiaoxin Line, and the Jiaoji Line, and they are connected to the three major ports in Qingdao, Yantai and Rizhao respectively. Relatively speaking, the railway transportation is more developed and the Jinan railway network is shown in Figure 2.

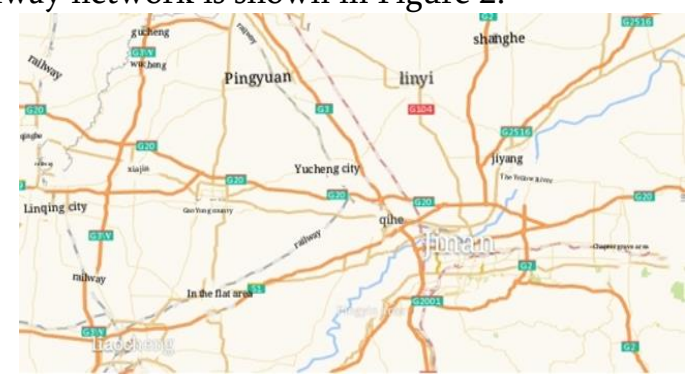

Fig.2. Ji'nan railway network

\subsection{Development of logistics information platform for multimodal transport center in Jinan}


In order to make the "Jinan multimodal transport cent er logistics information platform" smoothly exchanged ata with the user system, the development of interface must follow the principles of openness, extensibility, modularity, and standardization, which ensure the exp ansion of the "information platform" to reduce the cost of ma-intenance.

(1) Customs system interface

For the convenience of the platform users to carry out the bonded warehouse, the supervision of the warehouse, customs declaration and other business, " $\mathrm{i}$ nformation platform" must establish EDI interface with

customs system. Interface design must conform to cust oms data format requirements, and ensure effective co mmuni-cation with customs business system.

(2) Electronic data exchange (EDI) interface

EDI means to pass information through an electron ic data communication network in a set of common sta ndard formats specified by the protocol,

which exchanges and processes automatically between the computersystems of the business and trade partne rs. The "information platform" needs to develop the de sign standard EDI in--terface. ${ }^{[3]}$

(3) SMS platform interface

At present, almost everyone has a mobile phone, short message platform can be used as an effective way to realize the basis of logistics information platform, including China Mobile, China Unicom, China Mobile MMS and other operators with SMS protocol.

In addition, a WAP interface is also reserved for th e SMS platform to provide support for the mobile Inter net business in the later stage, providing online mobile phone query service and other functions.

(4) Other business interfaces

Provides EDI interfaces with railway, aviation, port, fire, security, public security, insurance and financial systems to provide related business services to users.

\section{Development Strategy of Multimodal Transport Center in Jinan City}

\subsection{Joint development and good investment opportunities}

In the process of developing multimodal transport, each city in Shandong should break its oppositional attitude and form a joint situation. All kinds of transport should explore each other's joint additive effect and speed up the development of multimodal transport in Shandong Province. At the same time, we can focus on developing businesses in regions where economic development is relatively rapid and where there are potential bulk sources of supply. We can collect more cargoes and long-distance FCL cargoes on cargoes to increase economies of scale. ${ }^{[4]}$

\subsection{Establish multimodal transport management information system}

Through the collection of electronic information, the transmission of electronic information and the exchange of electronic data, not only multimodal transport operators, container liner companies, shipping agencies, truck companies, railway transport companies, container terminal companies, freight forwarding companies and inland container freight terminals. People and other transportation departments are linked to each other, and they combine the consignee and consignor as well as the "one customs and three inspections", the foreign trade departments such as banks and insurance, and the regulatory inspection and service departments, thereby realizing the container information system. Rapid flow increases the efficiency of the entire multimodal transport.

\subsection{Straighten out the management system and remove obstacles}

The seamless and efficient connection of different modes of transport is a fundamental feature of multimodal transport. Specifically, while carrying out traffic infrastructure planning and construction, it is necessary to fully consider the effective convergence between different infrastructures to meet the demand for the development of multimodal transport. In particular, it is necessary to reform the current system of multimodal transport, build an integrated traffic management system, avoid multi-headed management, simplify intermodal procedures among various departments, and truly achieve seamless convergence of different modes of transport. In addition, we should also improve China's multimodal transport laws and regulations and increase enforcement. ${ }^{[5]}$

\subsection{Improve transport technology, innovate transport organization}

Accelerate research on high-speed and heavy-loaded railway freight transport, and promote the development of double-decker container transportation. With flexible and diverse forms of transport organization, in the current situation where container traffic is insufficient in inland areas, ordinary trains can be opened first, and container trains can be opened as the market grows and develops. In the direction of larger traffic, container trains or double-decker container trains may be opened, while 
multimodal transport operators are encouraged to contract contracted container trains, and multimodal transporters are used for sole proprietorship or joint ventures with railways. Various forms of container train operations.

\section{Conclusion}

The construction of the multimodal transport center in Jinan City is of great significance to the development of the current logistics; the construction of the multimodal transport center can reduce the accumulation of port cargo in inland hinterland and can improve the operating efficiency of the port. The multimodal transport center serves as a connection to the outside world. The bridge has a great effect on the economic development of inland areas. Based on this, it can increase the speed of development in inland areas. Under the new situation, there are many opportunities for the Jinan Multimodal Transport Center and it faces many challenges.

\section{References}

1. Zhu Xiaoning. Container Transport and Multimodal Transport $[\mathrm{M}]$. China Railway Publishing House, 2010.11.

2. Tao Jinghui. Layout Planning and Operation of Logistics Park $[\mathrm{M}]$. Beijing: China material Publishing House 2009.

3. $\mathrm{Hu}$ Yang.The Superiority of International Multimodal Transport [J]. Continental Bridge View, 2010, 08:58-59.

4. Zhang Zhihua. Development Countermeasures of International Multimodal Transport in China [M]. Water Transportation in China,2010(10).

5. Wang Wenjie. Brief discussion on the present situation and Development of China's International Container Multimodal Transport [M] .Entrepreneur 's World,2007(10). 